\title{
2-Dimethylaminoethanol (Deanol) in Huntington's chorea
}

\author{
T.A.CA R A C N I, F. G I R O T T I, I . C E L A NO, \\ E. P A R A T I, A N D L. B A L B O N I \\ From the Istituto Neurologico "C. Besta," Milan, Italy
}

SUMMARY A double-blind crossover trial with 2-dimethylaminoethanol (Deanol), a possible precursor of brain acetylcholine, was carried out in nine patients with Huntington's chorea. It was found to be ineffective in inducing any alteration in hyperkinesia.

The pharmacological treatment of Huntington's chorea has been based on the use of neuroleptic drugs, on the hypothesis that there is a functional dopaminergic hyperactivity in this illness (Agid, 1975).

More recently, after the observation of reduced cholinergic and GABAminergic activity at the striatal level in brains of choreic subjects (McGeer et al., 1973; Stahl and Swanson, 1974; Bird and Iversen, 1974), therapeutic trials were carried out with substances which facilitate the formation and persistence of these supposed neurotransmitters.

The hypothesis of reduced cholinergic activity at the striatal level is supported by the therapeutic effectiveness of physostigmine, a powerful anticholinesterase drug which also passes the bloodbrain barrier (Aquilonius and Sjöström, 1971; Klawans and Rubovitz, 1972; Davis et al., 1976). Nevertheless, this drug cannot be used clinically because of serious and numerous side effects.

Since then, there have been attempts to influence cholinergic metabolism by providing substances considered to be acetylcholine precursors. Dimethylaminoethanol acid (Deanol), a drug which has been proved to enhance the formation of acetylcholine in the CNS, has been shown to have effects on the CNS in animals (Pfeiffer et al., 1957; Haubrich et al., 1975), and in various pathological conditions in humans, such as schizophrenia, periodic headache, chronic states of fatigue, and bronchial asthma (Pfeiffer, 1958; Murphree et al., 1960).

With regard to extrapyramidal pathology, dimethylaminoethanol has been used for therapy of Huntington's chorea and tardive dyskinesia. In Address for reprint requests: Dr T. A. Caraceni, Istituto Neurologico
"C. Besta", Via Celoria 11, 20133 Milan, Italy.

Accepted 13 June 1978 these syndromes cholinergic hypofunction is considered to be one of the principal factors causing the clinical manifestations (Klawans, 1973).

The results obtained in tardive dyskinesia are ambiguous. In fact, some are positive (Miller, 1974; De Silva and Huang, 1975; Fann et al., 1975), and others are completely negative (Crane, 1975; Escobar and Kemp, 1975).

A clear-cut improvement in choreic abnormal movements was observed by Walker et al. (1973) during dimethylaminoethanol treatment of seven subjects with Huntington's chorea. At variance with this result, a worsening was described by Laterre and Fortemps (1975) in six out of seven subjects with Huntington's chorea. Previously these patients had been treated successfully with tetrabenazine and deterioration with dimethylaminoethanol should be considered to indicate a return to the pretetrabenazine state.

Considering the lack of agreement with regard to the effectiveness of dimethylaminoethanol in treatment of tardive dyskinesia, and because of the mall number of choreic patients who have been given this therapy, we report here the results obtained from a double-blind crossover study carried out in patients affected by Huntington's chorea.

\section{Subjects and methods}

We have examined nine hospital patients, six men and three women, between the ages of 16 and 63 years. The mean age was 49 years. Eight of the patients presented typical clinical pictures of Huntington's chorea characterised by varying degrees of choreic hyperkinesia, dementia, and autosomal dominant heredity. One patient (case 9) was considered separately from the others because 
of the age of onset (14 years) and because there was no hereditary transmission in his case (Table 1).

The severity of hyperkinesia was evaluated from videotapes as described by Caraceni et al. (1977a). Four neurologists assigned scores "blind" for four body territories (face, neck, trunk, and limbs) on a scale from 0 to 3 , where 0 represented absence of hyperkinesia, and 1 to 3 graded its severity and persistence. The final rating was the sum of the scores given by the four examiners. The worst score was 48 , the best, or normal, 0 . Hyperkinetic states were considered mild for scores from 1 to 16 , moderate from 17 to 32 , and severe from 33 to 48. Intellectual impairment was evaluated on the Wechsler-Bellevue scale. Intelligence quotients (IQ) ranged between 61 and 92. Deterioration was present in almost all the cases. There was no rigidity in any patient. Three patients had bulimia, and one was anorexic. Psychiatric disturbances were exhibited as paranoid ideation in one patient who attempted suicide, and as depression in another. The values for weight and height are reported in Table 1 . The patients were studied in a double-blind crossover trial of dimethylaminoethanol and a placebo, with random choice of the initial drug made by the hospital pharmacist.

Previous drug therapies were haloperidol in four patients and $\mathrm{N}$-(ethyl-2 pyrrolidinyl-methyl)-2methoxy-5-sulphamoil-benzamide (sulpyride) in two. The daily dose of haloperidol was $4 \mathrm{mg}$ for patients $1-3$, and $6 \mathrm{mg}$ for patients 2 and 6 ; and the duration of this treatment varied from six months to two years (Table 1). Sulpyride was administered at a dose of $400 \mathrm{mg}$ for six or 12 months (patients 7-9) (Table 1). These drugs were stopped not less than 15 days before the beginning of the study. The other patients (cases 4,5 , and 8 ) had not had any previous drug treatment.

The medications (dimethylaminoethanol or placebo) were administered in $200 \mathrm{mg}$ capsules, increasing the dose by $200 \mathrm{mg}$ every third day until the maximum dose of $1.0 \mathrm{~g}$ was reached. This level was maintained for seven days. After a drug-free interval of five days, another administration of medication was initiated in the same way. The trial lasted 40 days.

The hyperkinesia was evaluated under basal conditions and on maximum doses of placebo and dimethylaminoethanol.

The four patients who had been on haloperidol had been evaluated also on that treatment. The results were analysed statistically using Student's $t$ test. As an index of a single patient we scored the percentage change as follows: $\pm 25 \%$, no change; $\pm 50 \%$, moderately changed; and greater than $\pm 50 \%$, greatly changed. During the trial, all the patients underwent haematological tests, and hepatic and renal function tests.

\section{Results}

Table 2 indicates the hyperkinesia scores under the various conditions of the pharmacological trials under basal conditions, after placebo, and with the maximum dose of dimethylaminoethanol. Statistical analysis did not reveal any significant difference between therapy-free versus placebo, therapy-free versus dimethylaminoethanol, or placebo versus dimethylaminoethanol. The analysis of the results for each individual patient suggests there was an improvement in the hyperkinesia after treatment of five cases with dimethylaminoethanol. However, with the exception of case 4 , where a notable improvement was observed, the therapeutic effect was small, modifications of the scores under different therapies being less than $25 \%$.

In Table 3, the hyperkinetic scores of the four patients who received haloperidol therapy before the double-blind study were compared with those during dimethylaminoethanol treatment and

Table 1 Summary of data on study sample

\begin{tabular}{|c|c|c|c|c|c|c|c|c|c|c|c|c|c|c|}
\hline Patient & Sex & $\begin{array}{l}\text { Age } \\
(y r)\end{array}$ & $\begin{array}{l}\text { Duration } \\
\text { of illness } \\
(y r)\end{array}$ & Heredity & $I Q$ & $\begin{array}{l}\text { Severityof } \\
\text { hyperkinesia }\end{array}$ & Rigidity & $\begin{array}{l}\text { Height } \\
(\mathrm{cm})\end{array}$ & $\begin{array}{l}\text { Weight } \\
(k g)\end{array}$ & $\begin{array}{l}\text { Psychiatric } \\
\text { disturbance }\end{array}$ & $\begin{array}{l}\text { Anorexial } \\
\text { Bulimia }\end{array}$ & $\begin{array}{l}\text { Previo } \\
\text { Drug }\end{array}$ & $\begin{array}{c}\text { Dus trea } \\
\text { Dose } \\
(\mathrm{mg})\end{array}$ & $\begin{array}{l}\text { ment } \\
\text { Duration } \\
\text { (months) }\end{array}$ \\
\hline 1 & $\mathbf{F}$ & 29 & 6 & + & 61 & Moderate & - & 148 & 45 & - & Bulimia & Hal & 4 & 24 \\
\hline 2 & $\mathbf{M}$ & 54 & 9 & + & 92 & Moderate & - & 190 & 83 & - & Bulimia & Hal & 6 & 12 \\
\hline 3 & $\mathbf{F}$ & 43 & 2 & $\div$ & 73 & Moderate & - & 154 & 44 & Depression & - & Hal & 4 & 6 \\
\hline 4 & $\mathbf{M}$ & 28 & 2 & $i$ & 71 & Mild & - & 162 & 66 & - & - & \multirow{2}{*}{\multicolumn{3}{|c|}{$\begin{array}{l}\text { No therapy } \\
\text { No therapy }\end{array}$}} \\
\hline 5 & $\mathbf{M}$ & 63 & 3 & $\div$ & 62 & Severe & - & 160 & 63 & - & - & & & \\
\hline 6 & $\mathbf{M}$ & 63 & 6 & + & 86 & Severe & - & 162 & 69 & - & - & Hal & 6 & 24 \\
\hline 7 & $\mathbf{M}$ & 33 & 4 & + & 89 & Severe & - & 176 & 65 & - & Anorexia & Sul & 400 & 12 \\
\hline 8 & $\mathbf{F}$ & 61 & 10 & + & 72 & Moderate & - & 170 & 50 & $\begin{array}{l}\text { Attempted } \\
\text { suicide }\end{array}$ & Bulimia & No th & lerapy & \\
\hline 9 & $\mathbf{M}$ & 14 & 2 & $\ldots$ & 83 & Moderate & - & 172 & 65 & - & - & Sul & 400 & 6 \\
\hline
\end{tabular}

Hal = haloperidol.

Sul $=$ sulpyride. 
Table 2 Hyperkinesia scores under basal conditions, after placebo, with dimethylaminoethanol

\begin{tabular}{llll}
\hline Patient & No therapy $(N T)$ & Placebo & Dimethylaminoethanol \\
\hline 1 & 30 & 28 & 25 \\
2 & 19 & 20 & 15 \\
3 & 23 & 25 & 27 \\
4 & 16 & 16 & 11 \\
5 & 35 & 33 & 32 \\
6 & 40 & 40 & 48 \\
7 & 40 & 34 & 34 \\
8 & 23 & 28 & 23 \\
9 & 20 & 18 & 20 \\
\hline
\end{tabular}

Student's $t$ test analysis

NT versus placebo-NS.

NT versus dimethylaminoethanol-NS.

Placebo versus dimethylaminoethanol-NS.

Table 3 Hyperkinesia scores under basal conditions, after dimethylaminoethanol, and after haloperidol

\begin{tabular}{llll}
\hline Patient & No therapy $(N T)$ & Dimethylaminoethanol & Haloperidol \\
\hline 1 & 30 & 25 & 23 \\
2 & 19 & 15 & 15 \\
3 & 23 & 27 & 18 \\
6 & 40 & 48 & 29 \\
\hline
\end{tabular}

NT versus haloperidol- $P<0.05$

NT versus dimethylaminoethanol-NS

Dimethylaminoethanol versus haloperidol-NS

under basal conditions. Statistical analysis demonstrated a significant difference $(P<0.05)$ between the values obtained under basal conditions and those after haloperidol therapy. On the other hand, no significant difference was noted between treatment with dimethylaminoethanol and basal conditions.

All the toxicity tests were negative, and no side effects were noted.

\section{Discussion}

This pharmacologic trial of dimethylaminoethanol (Deanol) in the treatment of Huntington's chorea has shown no useful activity of the drug. In fact, the statistical analysis of paired data in nine cases did not demonstrate any significant difference in hyperkinetic symptoms between basal conditions and active therapy, or between the scores obtained while on placebo or dimethylaminoethanol. Furthermore, no therapeutic effect was observed in the individual cases, comparing the scores before and after dimethylaminoethanol, except for case 4 in whom the difference in the scores was greater, while a significant reduction of hyperkinesia had been induced by haloperidol treatment in four cases. These results confirm our previous observations on the effects of physostigmine and haloperidol (Caraceni et al., 1977b), and contradict the observations of Walker et al. (1973) who ob- tained positive results in five of seven patients with Huntington's chorea, using doses similar to those administered by us.

Our data do not support the concept of reduced activity of choline acetyltransferase in the basal ganglia in Huntington's chorea. The hypothesis of reduced cholinergic tone in Huntington's chorea is supported by the evidence of low cerebrospinal fluid choline levels (Aquilonius et al., 1975; Consolo et al., 1977), by the therapeutic effectiveness of cholinesterase inhibitors, and by the clinical worsening observed during anticholinergic treatment (Klawans and Weiner, 1976).

The disagreement between the theoretical data and our present results may be explained as follows.

Firstly, the dosage used by us may be insufficient to furnish the quantity of precursor necessary to provoke a valid modification in CNS levels of acetylcholine. On the other hand, the doses of dimethylaminoethanol which we used were perfectly comparable to those adopted by other workers. It seems to us that the data reported in the literature on the effectiveness of cholinomimetic substances in choreic hyperkinesia are not convincing and, in fact, the results ascribed to physostigmine are not always concordant (Tarsy et al., 1974).

Secondly, it is possible that dimethylaminoethanol is not metabolised to acetylcholine in sufficient quantity. This hypothesis is supported by the absence of signs of cholinergic stimulation. Studies in a variety of experimental animals did not demonstrate any central cholinergic effect of dimethylaminoethanol (Pepeu et al., 1960; Weiner et al., 1976).

Thirdly, it is true that activity of choline acetyltransferase is clearly reduced and that the ratio of tyrosine hydroxylase to choline acetyltransferase is decisively altered in favour of the former. Correction of this altered relationship should be beneficial. It has also been noted that the reduced level of choline acetyltransferase in the basal gangia must be caused by a substantial loss of Golgi type 2 cells, particularly in the caudate nucleus and putamen which are for the most part cholinergic cells. For this reason it is possible that the unsuccessful use of acetylcholine precursors or of acetylcholine itself is due to the serious reduction in cholinergic neurones.

Drugs which directly stimulate cholinergic receptors might be expected to induce beneficial effects, but this has not been confirmed by the observations of Chase et al. (1976) who treated patients with pilocarpine, a cholinergic receptor stimulant, and found no clinical improvement. 
Furthermore, the reduction in activity of choline acetyltransferase was not verified in the brains of all the choreic patients, but only in 23 out of 37 cases by Bird and Iversen (1974). This observation would account for a certain diversity in responsiveness recorded in different studies.

As many different enzymes may be involved or impaired in Huntington's chorea, for instance glutamic acid decarboxylase, and angiotensin converting enzyme (Arregui et al., 1977), and as there are interactions between the different neurotransmitters, it is possible that treatment with a medication which acts solely on the cholinergic system would be unable to induce detectable results.

We thank Pharmaton SA, Lugano-Bioggio, for the supply of 2-dimethylaminoethanol (Deanol), and Mrs A. Magatti for her secretarial assistance.

\section{References}

Agid, Y. (1975). Approche neuropharmacologique de la chorée de Huntington. Revue Neurologique, 131, 847-865.

Aquilonius, S. M., and Sjöström, R. (1971). Cholinergic and dopaminergic mechanisms in Huntington's chorea. Life Sciences, 10, 405-414.

Aquilonius, S. M., Eckernäs, S. A., Sundwall, A. (1975). Regional distribution of choline acetyltransferase in the human brain: changes in Huntington's chorea. Journal of Neurology, Neurosurgery, and Psychiatry, 38, 669-677.

Arregui, A., Bennett, J. P., Bird, E. D., Yamamura, H. I., Iversen, L. L., and Snyder, S. H. (1977). Huntington's chorea: selective depletion of activity of angiotensin converting enzyme in the corpus striatum. Annals of Neurology, 2, 294-298.

Bird, E. D., and Iversen, L. L. (1974). Huntington's chorea: post mortem measurement of glutamic acid decarboxylase, choline acetyltransferase and dopamine in basal ganglia. Brain, 97, 457-472.

Caraceni, T., Calderini, G., Consolazione, A., Riva, E., Algeri, S., Girotti, F., Spreafico, R., Branciforti, A., Dall 'Olio, A., and Morselli, P. L. (1977a). Biochemical aspects of Huntington's chorea. Journal of Neurology, Neurosurgery, and Psychiatry, 40, 581-587.

Caraceni, T., Giovannini, P., Girotti, F., and Avanzini, G. (1977b). Pharmacology of Huntington's chorea. European Neurology, 16, 42-50.

Chase, T. N., Kartzinel, R., and Shoulson, I. (1976). Effect of pilocarpine in Huntington's chorea. Unpublished observations cited in The Basal Ganglia. Edited by M. Yahr. Raven Press: New York.

Consolo, S., Ladinsky, H., Bianchi, S., and Caraceni, T. (1977). The cerebrospinal fluid choline levels in patients with Huntington's chorea. Negative effect of haloperidol treatment. Archiv für Psychiatrie und Nervenkrankheiten, 223, 265-270.
Crane, G. E. (1975). Deanol for tardive dyskinesia. New England Journal of Medicine, 292, 926-927.

Davis, K. L., Hollister, L. E., Barchas, J. D., and Berger, P. A. (1976). Choline in tardive dyskinesia and Huntington's chorea. Life Sciences, 19, 15071516.

DeSilva, L., and Huang, C. Y. (1975). Deanol in tardive dyskinesia. British Medical Journal, 3, 466.

Escobar, J. I., and Kemp, K. F. (1975). Dimethylaminoethanol for tardive dyskinesia. New England Journal of Medicine, 292, 317-318.

Fann, W. E., Sullivan, J. L., Miller, R. D., and McKenzie, G. M. (1975). Deanol in tardive dyskinesia: A preliminary report. Psychopharmacologia, 42, 135-137.

Haubrich, D. R., Wang, P. F. L., Clody, D. E., and Wedeking, P. W. (1975). Increase in rat brain acetylcholine induced by choline or deanol. Life Sciences, 17, 975-980.

Klawans, H. L. (1973). The pharmacology of tardive dyskinesias. American Journal of Psychiatry, 130, 82-86.

Klawans, H. L., and Rubovitz, R. (1972). Central cholinergic-anticholinergic antagonism in Huntington's chorea. Neurology (Minneapolis), 22, 107116.

Klawans, H. L., and Weiner, W. J. (1976). The pharmacology of choreatic movement disorders. Progress in Neurobiology, 6, 49-80.

Laterre, E. C., and Fortemps, E. (1975). Deanol in spontaneous and induced dyskinesia. Lancet, 1, 1301.

McGeer, P. L., McGeer, E. G., and Fibiger, H. C. (1973). Choline acetylase and glutamic acid decarboxylase in Huntington's chorea. Neurology (Minneapolis), 23, 912-917.

Miller, E. M. (1974). Deanol: a solution for tardive dyskinesia? New England Journal of Medicine, 291, 796-797.

Murphree, H. B., Pfeiffer, C. C., and Backerman, I A. (1960). The stimulant effect of 2-dimethylaminoethanol (Deanol) in human volunteer subjects. Clinical Pharmacology and Therapeutics (St Louis), 1, 303-310.

Pepeu, G., Freedman, D. X., and Giarman, N. J. (1960). Biochemical and pharmacological studies of dimethylaminoethanol (Deanol). Journal of Pharmacology and Experimental Therapeutics, 129, 291295.

Pfeiffer, C. C. (1958). Deanol: a biochemical stimulant. Modern Hospital, 9, 76-79.

Pfeiffer, C. C., Jenney, E. H., Gallagher, W., Smith, R. P., Bevan, W., Killam, K. F., Killam, E. K., and Blackmore, W. (1957). Stimulant effect of 2dimethylaminoethanol-possible precursor of brain acetylcholine. Science, 126, 610-611.

Stahl, W. L., and Swanson, P. D. (1974). Biochemical abnormalities in Huntington's chorea brains. Neurology (Minneapolis), 24, 813-819.

Tarsy, D., Leopold, N., and Sax, D. S. (1974). Physostigmine in choreiform movement disorders. Neurology (Minneapolis), 24, 28-33. 
Walker, J. E., Hoehn, M., Sears, E., Lewis, J. (1973). Weiner, W. J., Kanapa, D. J., and Klawans, H. L. Dimethylaminoethanol in Huntington's chorea. Lancet, 1, 1512-1513.

(1976). The effect of dimethylaminoethanol (Deanol) on amphetamine-induced stereotyped behaviour (AISB). Life Sciences, 19, 1371-1376. 